\title{
Crystal structure of lanthanum silver aluminium, $\operatorname{LaAg}_{0.6} \mathbf{A l}_{3.4}$
}

\author{
G. Cordier, C. Dietrich and G. Doersam
}

Technische Hochschule Darmstadt, Zintl-Institut, Anorganische Chemie II, Hochschulstr. 10, D-64289 Darmstadt, Germany

Received August 1, 1996, transferred to 2nd update of database ICSD in 1997, CSD-No. 402575

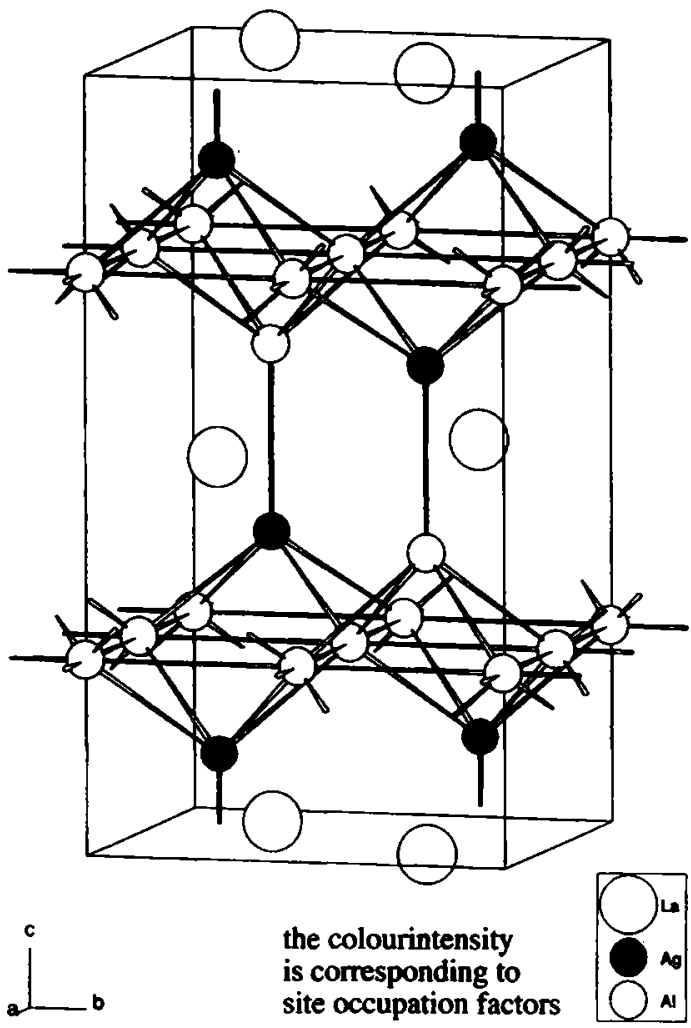

Source of material: The compound was prepared from the elements (purity min. 99.9 mass\%) at $1273 \mathrm{~K}$ in corundum crucibles in argon atmosphere:

In the crystal structure of LaAg0.6Al3.4, a new variant of the $\mathrm{ThCr}_{2} \mathrm{Si}_{2}$-type, the A12-atoms form plain $4^{4}$-nets perpendicular to [001] at $z=0.2498$ and $z=0.7502$. The Agl/Al1 - , the Ag2/Al2and the Al3-atoms are located alternately above and below the sqares of the $4^{4}$-nets forming layers of edge-sharing $T, X$-pyramids. Thereby the Al3-atoms occupy in an ordered way one fourth of the pyramid-top. The other three fourth of these positions are occupied statistically by $\mathbf{A g} / \mathbf{A l}$-atoms. The pyramid-layers are staggered along [001] in such a distance, that reciprocal actions between the $\mathrm{Al} 3$ - and $\mathrm{Ag} / \mathrm{Al}$-atoms respectively $\mathrm{Ag} / \mathrm{Al}$ - and $\mathrm{Ag} / \mathrm{Al}$-atoms occur (distances $249.6 \mathrm{pm}$ and $269.0 \mathrm{pm}$ ) The La-atoms are located between these layers occupying the centers of two tetragonal prisms formed by four $\mathrm{Al} 3-$, four $\mathrm{Ag} 2 / \mathrm{Al} 2$ and eight Al4-atoms respecively eight Ag2/Al2-and eight Al4-atoms.

Ag0.6Al3.4La, tetragonal, P4/nmm (No. 129), $a=6.180(2) \AA$, $c=11.051(4) \AA, V=422.1 \AA^{3}, Z=4, R(F)=0.055, R_{w}\left(F^{2}\right)=0.173$.

Table 1. Parameters used for the X-ray data collection

\section{Crystal:}

Wavelength:

$\mu$ :

Diffractometer:

Scan mode:

$T_{\text {measurement: }}$

$2 \theta_{\max }$ :

$\mathbf{N}(h k l)_{\text {unique: }}$

Criterion for $I_{0}$ :

$\mathrm{N}$ (param) refined.

Program:

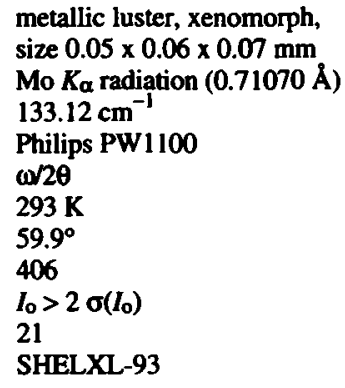

Table 2. Final atomic coordinates and displacement parameters (in $\AA^{2}$ )

\begin{tabular}{|c|c|c|c|c|c|c|c|c|c|c|c|}
\hline Atom & Site & Occ. & $x$ & $y$ & $z$ & $U_{11}$ & $U_{22}$ & $U_{33}$ & $U_{12}$ & $U_{13}$ & $U_{23}$ \\
\hline $\operatorname{La}(1)$ & $2 c$ & & $1 / 4$ & $1 / 4$ & $0.0016(1)$ & $0.0000(5)$ & $U_{11}$ & $0.0000(7)$ & 0 & 0 & 0 \\
\hline $\mathrm{La}(2)$ & $2 b$ & & $3 / 4$ & $1 / 4$ & $1 / 2$ & $0.0000(5)$ & $U_{11}$ & $0.0000(7)$ & 0 & 0 & 0 \\
\hline $\mathbf{A g}(1)$ & $2 c$ & $0.50(1)$ & $1 / 4$ & $1 / 4$ & $0.3753(2)$ & $0.002(1)$ & $U_{11}$ & $0.003(2)$ & 0 & 0 & 0 \\
\hline Al(1) & $2 c$ & 0.50 & $1 / 4$ & $1 / 4$ & $0.3753(2)$ & $0.002(1)$ & $U_{11}$ & $0.003(2)$ & 0 & 0 & 0 \\
\hline $\mathrm{Ag}(2)$ & $4 f$ & $0.298(9)$ & $3 / 4$ & $1 / 4$ & $0.1206(2)$ & $-0.001(1)$ & $-0.001(1)$ & $0.004(1)$ & 0 & 0 & 0 \\
\hline Al(2) & $4 f$ & 0.702 & $3 / 4$ & $1 / 4$ & $0.1206(2)$ & $-0.001(1)$ & $-0.001(1)$ & $0.004(1)$ & 0 & 0 & 0 \\
\hline Al(4) & $8 j$ & & $0.0030(3)$ & $x$ & $0.7502(2)$ & $0.002(1)$ & $U_{11}$ & $0.000(2)$ & 0 & $0.001(2)$ & $U_{13}$ \\
\hline
\end{tabular}

\section{References}

1. Doersam, G.: Zur Darstellung und Strukturchemie von Seltenerd-Übergangsmetall-Aluminium bzw. Element (IV)-Verbindungen. Thesis, University of Darmstadt, Germany 1990.

2. Sheldrick, G. M.: SHELXL-93, a program for refining crystal structures. University of Göttingen, Germany 1993. 